\title{
Design and Analysis of the Third-party Logisitics Management System Based on J2EE
}

\author{
Hao li-xia ${ }^{1, a}$, Zhao Feng-qing ${ }^{2, b}$ Jia Shu-hong $^{3}$ Ma Chao-hua ${ }^{3}$ \\ ${ }^{1}$ Hebei Chemical and Pharmaceutical College of Vocational Technology, Shijiazhuang050026 PRC \\ ${ }^{2}$ Chemical Dept. of Hebei University of Science \& Technology, Shijiazhuang 050018 PRC \\ ${ }^{3}$ Hebei Jiheng (Group) Pharmaceutical Co.,Ltd, Hengshui 053000, China \\ aHaolixia2006@126.com, 'bhaofq3366@126.com (corresponding author)
}

Keywords: J2EE ; Distribution requirements planning; Logisitics management

\begin{abstract}
The analysis and design ideas of third party logistics management information systems were introduced based on the research for a company in Beijing, China. With distribution requirements planning ( DRP) system, data sharing can be realized effectively and are transparent to the existing system with scalability. The third-party logistics information management system developed based on this proposal has been put into operation, and solved the resource sharing problem inside a logistics company.
\end{abstract}

\section{Introduction}

DRP module can be used in many sales-related departments in a company, such as the sales headquarters, the branch / business department, office, finance, inventory management, in order to achieve efficiency of individual business management ${ }^{[1-3]}$. Third-party logistics companies can replace the manual work with DRP system to undertake a variety of work of business data statistics, analysis, sorting, and report, greatly improving efficiency and reducing operating costs.

In this paper, some ideas on the analysis and design of third party logistics management information systems were discussed.

\section{Requirements analysis of the third-party logistics information}

Distribution Resource Planning System. In this project, the logistics information system to be achieved is a very typical DRP system, which is an information system connecting the manufacturing enterprise with goods consignee, mainly performing transportation, warehousing, distribution and other related operations. In the field of information technology in the enterprise, it mainly concerns the location, number, status, ownership and other changes. DRP system achieved the information integration of logistics and capital flow in the finished goods supply chain (while ERP is the entire supply chain).

The project undertakes transportation, warehousing and distribution operation between promotional products/business gifts manufacturers and retailers. Although the project information system possesses typical third-party property management information system characteristics, it carries advanced thinking of supply chain management. It needs to put the supply-side and the demand-side on supply chain management, which can assist the customers to achieve the following objectives:

- Optimizing the relationship between the upstream and downstream partners

- Value innovation to meet the requirements of customers

- Eliminate ineffective operations and waste

- Focused on solving the constraints (bottlenecks)

- Optimize the supply chain continuously.

In this project, it involves many enterprises on the supply chain, including suppliers of various manufactured products, its partners, the demand side, the consignee, etc.. 


\section{System function requirement analysis}

\section{Customer analysis}

In this project, users of information system may include:

- Supplier

- Company and its departments

- Storage supplier

- Transportation supplier

- Consumer

\section{Main process analysis}

From the aspect of the branch of transportation agency of the company, there are three main steps: warehousing process, discharging process, storage management process

\section{Main function analysis}

We made a detailed analysis of system function requirement, its functions can be divided into the following specifications:

- Customer requirement management (customer service order management)

Customer requirement management function mainly fulfills the demands from customer, for instance: transportation entrusting demands; warehouse order demands; discharge order requirements. Main user of the function include: customer from the branch of company's transportation agency, products consumer.

- Transportation management

Transportation management function mainly serves inside the company. Its function is to help company finish the confirmed order from customer. Customer confirmed transportation entrusting order should be established an internal business of the company, so as called a transportation task.

- Storage management

Storage management function is mainly for administrator of the storage and related people of other cooperative storage supplier. Here it refers to the major storage, regional storage and minor storage. Storage management work mainly achieves the warehousing management, discharge management, storage management, stock count management, account.

The warehousing management involves the above mentioned warehousing order of customer requirement management. Here we separate storage warehousing task with warehousing order. We would like to put forward a word: goods arrival plan. Warehousing order should go with goods arrival plan in the goods details. Warehousing order is from the aspect of customer, and goods arrival plan is from the aspect of the storage.

- Financial management

Financial management mainly provides basis for financial settlement, including accounts receivable and account payable.

- Exterior information service

This function mainly provides all kinds of information service to each customer of the branch of company's transportation agency.

It mainly include: transportation entrusting order inquiry, storage details inquiry, account diary inquiry, entrusting transportation order management inquiry and the bill query between the company and transportation agency branches.

Meanwhile, besides information service, some detailed statistical analysis of their own goods can be also provided to the customer, which mainly includes: statistical analysis of themes according to promotion activity/business activity material use and transportation fees; statistical analysis of themes according to customer type material use.

- Statistical analysis \& assistant decision-making

This function is to use IT technology to provide transportation agency with knowledge service. From the technical aspect, mainly provide instant inquiry and OLAP service.

Instant inquiry can make all kinds of inquiries of follows: 
- Customer entrusting order by time

- Customer entrusting order by batch

- Customer entrusting order by single item

- Customer entrusting order by promotion activity

- Customer entrusting order by user's customer

- Customer entrusting order by region

- Customer entrusting order of all customers

OLAP will achieve Statistical analysis:

- Warehousing income statistical analysis

- Transportation income statistical analysis

- Transportation cost statistical analysis

- Transportation benefit statistical analysis

- Transportation operation indicator statistical analysis

Besides, the project can also provide the supplier with apply and verify function that can help the customer pick up the goods, and inform the related staff of transportation agency.

To support all the above functions, this project needs some supportive functions, including:

- System management

Mainly manage user's account, role and right.

- Goods resource management

Mainly manage company and its partner's goods resource, which includes information for storage and vehicle of each company.

- Customer management

Besides the service of transportation, storage and delivery provided to transportation agency's customer and available transportation resources; customer resource management is needed, which mainly includes: customer's goods specification, customer's goods supplier, customer's goods consumer, all information of customer's goods consumer's consignee and the warehouse of the customer.

\section{Design of informatization plan for the third partner logistics}

According to the 'function requirement instruction' offered by customer, this project is supposed to be a typical informatization system of the third partner logistics enterprise and on the supply chain, an EDI data center needs to set up, based on which, customer demands management center, transportation information management center, storage information management center, financial information management center, abnormal information management center and so on five business management center should be set up. On this base, exterior comprehensive information service platform and assistant decision-making platform need to be set up.

Company logistics informatization systematic structure. The whole system is set up on the basic net platform of the internet and company internal local area network. The whole software system is established on the internet, and company internal area network can access in to internet and visit the software system through special line or ADSL.

On the basic net platform, there is a hardware platform consist of computer hardware system, such as host computer server, storage, backup, security and other devices. The application server software, database software, workflow software, analysis software constitute the basic software supportive environment of the system.

Based on the basic software supportive environment, logistics information system is developed, whose business function mainly include customer demands management system, transportation management system, storage management, financial management system and exterior comprehensive information service system. The control functions include system control, logistics resource control, customer control three systems. The control function provides data support to business function. 
Logistics information system mainly provides related function to company, its partner, customer, and customer's users.

Above all, and the uniform standards, security guarantee, logistics service management system and teams, formed the complete logistics information systematic structure.

Technical line and products specification. This project mainly adopts J2EE technic, relational database, workflow technology and role-based access control.

\section{Technical line}

- J2EE technology

According to the construction requirement, we adopt J2EE technical line as the technical structure of the logistics information system. It is also for the purpose of Portable and scalable in the future. Meanwhile, we also take the multiple platforms to promote the company's informatization.

J2EE technical structure is suitable for the multiple layers model, and it uses module based type to design, develop, install and apply to the big system. XML based data exchange, uniform security model and flexible management; all these can provide brand new solution to the fast changing demands. What's more the product is J2EE solution that is not related the platform, and does not rely on one special products or API. That is to say, both the company and the customer are free to choose the products or module that is more helpful to their business or technical demands. It is good to reduce the cost and can meet the customers' changing needs.

- Relational database

Meanwhile, this project will adopt big relational database as the data storage medium of all kind of business figures. The usual business data base manufacturer on the present market includes Oracle, Microsoft SQL Server and other big relational database.

- Workflow technology

This project relates to many business process controls, therefore, workflow control technology is needed. Workflow refers to computerize or electronic the above business process in computer application, that is to say, to use computer technology to fulfill the atomization of business dealing process (running, monitoring, analyzing and so on) .

Workflow management coalition (WfMc) defines the workflow as: it is a kind of business process that can fully or partly execute automatically, according to series process rules, documents, information or task can pass and execute among different executors.

- Role based access control

Role based access control technology is very popular in the business application, because it can reduce the complexity and cost of the security management in the big web applications. Role, rank, and rules control the rights to reduce the security works. Role based access control offers a safe and effective security management to business application system and reduce the cost and errors in security management.

\section{Basic software specification}

According to the construction requirement of this project, Apache Tomcat as the J2EE application server software were used, and Oracle or Microsoft SQL Server was adopted as the database software.

The engine of workflow software uses LiquidFlow Suite packages.

Business model consists of database design, business model API and business model access API. Business model API uses engine design style, that is, to access business applications need to use the logistics business functions, simply access the API through the business model with the engine, all the logistics business functions can be accessed.

\section{Conclusion}

The third-party logistics information management system developed based on this proposal has been put into operation, and solved the resource sharing problem inside a logistics company. It is convenient and flexible, with low development costs and better integration and scalability and so on. 


\section{References}

[1] Bozarth, $\mathrm{CC}$ introduction to operation and supply chain management [M] Beijing Tsinghua University press, 1999

[2] Zhang Jingda, Hou Junxia. Development and application of capital management information system. Micro Computer Information 2010(21),p36. (In Chinese)

[3] Yanbin, ERP analysis and design of Web Service based agile manufacturing enterprises coalition. Journal of Jiangsu University of Science and Technology (Edition of Natural Science). 2009.5 